\title{
Pervasive electrochemistry
}

\author{
Achim Walter Hassel ${ }^{1}$
}

Received: 15 July 2020 / Revised: 15 July 2020 / Accepted: 17 July 2020 / Published online: 4 August 2020

(C) The Author(s) 2020

\section{Electrochemistry}

With last year's Nobel Prize for the development of lithium ion batteries, electrochemistry as a discipline was well recognized by a broader scientific community and the society itself. This is however only one aspect of the importance of electrochemistry for solving our energy problems. Lots of attempts are presently made to tackle the global climate challenge. There is a large number of attempts such as avoiding $\mathrm{CO}_{2}$ emission by using regenerative energy (batteries required), reducing $\mathrm{CO}_{2}$ emission by changes in the process, for example, to fuel cells with higher efficiency (cheap and efficient electrocatalysts required), reuse of produced $\mathrm{CO}_{2}$ to generate fuels or produce compounds which are presently made from natural gas or oil. Also the steps into an extended use of hydrogen as energy carrier require electrochemical processes during production and use.

A principal advantage of electrochemistry is that it is directly linking chemical reactions and electrical voltage/current. This allows driving chemical reactions with electrical energy on one side but also yield electrical signals from chemical reactions through sensors which can be directly processed further electronically.

For sure the importance of electrochemistry will grow further and will pervade our daily life. Let us have a look into why and how this is happening and where are the future tasks for us as electrochemists or scientist entering this field.

\section{Electrochemical equipment}

The general trend to smaller, faster and cheaper electronics with higher integration and extended methodology is also

Achim Walter Hassel

achimwalter.hassel@jku.at

1 Institute of Chemical Technology of Inorganic Materials (TIM), Johannes Kepler University Linz, Altenberger Str. 69, 4040 Linz, Austria driving developments in electrochemistry. Today, highly integrated electronic circuits do not only provide the electronics of a potentiostat but combine it with signal generation such as potential steps, ramps for cyclic voltammetry (CV) or (sets of) sine waves for electrochemical impedance spectroscopy (EIS). Data acquisition is fast enough to enable high scan rates in CVs or sampling in the time domain for FFT EIS or electrochemical noise. Embedded CPUs are powerful enough to run lots of firmware or software to complement the hardware to fully operational (miniaturized) electrochemical workstations. Further decreasing prices per unit will allow even wider distribution as well as higher parallelization, e.g. for massively parallel testing of batteries. These devices are ready to enter other fields.

\section{Electrochemistry in production}

On the verge of fossil energy to renewables, the importance of electrochemical production will further increase. What is already seen in the shift or transition from pyrometallurgical to electrochemical hydrometallurgical processes such as the production of zinc is the increasing consideration of the advantages of electrochemical processing. These electrochemical processes usually run at near ambient temperatures $\left(<100{ }^{\circ} \mathrm{C}\right)$ and thus require only cheaper materials. Molten salt electrolyses for $\mathrm{Al}$, $\mathrm{Li}, \mathrm{Mg}$ and Na production operate at higher temperatures but do not really have chemical alternatives. Controlling voltage or current makes it possible to operate an electrochemical reaction faster or slower to optimize it for lowest costs per ton of product or to produce as much as possible if the demand is high (e.g. chlor-alkali electrolysis). Such an alteration does not require changes in the electrochemical reactor but is impossible or much more difficult in chemical reactors which are designed for a certain compound flux and energy flux. This elasticity of production within one line can easily adapt to day/night changes and changes in wind intensity.

Recycling rates must increase. Tremendous amount of energy are being saved when using recycled material rather than 
ores as it is already realized for $\mathrm{Al}, \mathrm{Fe}$ and $\mathrm{Cu}$. Urban mines, i.e. electronic scrap and other wastes that contain valuable metals, contain significant amounts of noble metals (Ag, Au, $\mathrm{Ir}$, Os, Pd, Pt, Rh, Ru) which are collected, concentrated and fed to the electrochemical copper refining. Such electrochemical recycling is not only important for the winning of metals but also for the depletion of wastes, e.g. to reduce not only amounts of potentially poisonous elements (As, $\mathrm{Cd}, \mathrm{Hg}$, In, $\mathrm{Sb}, \mathrm{Se}, \mathrm{Te}, \mathrm{Tl}$,) but also valuable alloying elements $(\mathrm{Cr}, \mathrm{Ni}$, Mo, W).

A further shift from chemical synthesis to electrochemical synthesis is desirable. Using captured $\mathrm{CO}_{2}$ or industrial exhaust $\mathrm{CO}_{2}$ as source for chemical base chemicals means killing two birds with one stone. It is used as a chemical source and reduces the greenhouse gas emission. This should be only the first step. Replacement of highly oxidizing or highly reducing agents reduces risks and many other challenges. Advantageous would be a wider portfolio of electrochemical and bioelectrochemical syntheses routes.

\section{Medical electrochemistry}

These days one could wish to have systems and materials with in situ generation of disinfectants. Here, electrochemistry may be a way to produce reactive species that are killing viruses, bacteria and other germs.

It may sound like a late appreciation of Luigi Galvani's experiments that stimulating muscles can save lives and improve living quality. While the brute force of a heart defibrillator stimulates many more muscles than necessary, a proper functioning pace maker stimulates in a much more sophisticated way, and even elderly people who cannot take a surgery may be treated when an intracardiac pacemaker such as the Micra TM is used. While this device with a non-rechargeable battery and a lifetime of some 10 years was initially thought to be the final treatment of high age patients, it may sound ludicrous that this device improves the health so efficiently that it requires replacement and thus devices that can be easily explanted [1]. Many more devices are now used as stimulating implants like cochlea implants (CI) for hearing aids, functional electrical stimulation to treat stroke, incontinence, apnoea or epilepsy. Further stimulations are manifold, and with the ageing society, we need to work on more solutions. Besides the pure number of applications, it is a challenge to treat both the afferent and the efferent system; in case of a CI that would allow controlling the external electronics of the hearing aid by the brain itself and thus closing the auditory loop. Work on other senses is going on as well.

\section{High throughput and combinatorial electrochemistry}

With the experimental developments, it becomes easier and more feasible to perform true parallel electrochemical experiments as it is done today already in battery testing [2]. One may argue that this is no real research. But in fact when addressing questions of optimization and exploration of parameter fields, e.g. concerning durability and reproducibility, it is necessary to generate lots of experimental data. If all of this is done under well-controlled conditions, in parallel, the resulting differences or similarities can be clearly and reliably assigned to the experimental parameters altered. Once such differences have been identified, the scientific reason behind may be explored in another development cycle. It is a long known tradition to study materials by changing, for example, the concentration of an alloying element on the corrosion stability or the electrochemical activity towards a reaction of interest. Then, it is simply highly consequent to refine this approach and to study material libraries, for example, with compositional lateral gradients or dedicated synthesis products. Lots of localized electrochemical methods allow nowadays an efficient screening of electrochemical properties and/ or reactions such as SKP (scanning Kelvin probe) or SDCM (scanning droplet cell microscopy). Ideally, those studies are performed by automated systems. As the history of all compositions is identical, the experimental scattering is reduced, and rather coherent sets of experimental data are obtained. This data is valuable in the sense that it is very comprehensive. In some cases, however, an unexpected very drastic change or an extremum is found. This so-called hit is not only interesting in optimization; rather scientific curiosity will then be driven into finding out why this unexpected behaviour occurs. This is what convinced the author of this article to use such an approach in various fields of electrochemistry, to setup a large and versatile research cluster that invites discussions about joint research.

\section{Electrochemical big data}

The above-described experimental approach may be seen as part of the materials' genome project. For sure, it will be complemented by results from theoretical attempts such as DFT. Efficient code, highly parallel computing in GPUs rather than CPUs, larger computing clusters and distributed systems will all contribute to the generation of much more data. The representation of data will be extended. Text-based search is presently changing towards image recognition. This field will further grow, and with the rise of artificial intelligence, it will bring us far beyond today's expert systems for single methods "to boldly go where no one has gone before" [3]. 


\section{Pervasive electrochemistry}

Dramatic changes were seen from the rise of the first mobile phones to today's high performance smartphones. Who would have considered that a camera will be implemented or even complemented by a front camera, a gyrometer, an accelerometer and so on? Using the IR sensitivity of the camera not only for checking the function of ones remote control but also as a pyrometer shows that the fantasy is unbroken. Why should one doubt that electrochemical sensors will make it soon into these widely distributed personal devices? The market for more and new features is there. Lab on the chip can quickly analyse the health condition (glucose, INR) and warn us from personal risks when doing sports or entering contaminated places, may it be biologically, chemically or physically. This can also generate a request for developing cheap (e.g. glucose) sensors that can be readily shared with underprivileged societies [4]. When extending our own perception by means of such a device, it is to be expected that electrochemistry will play an important role.

This will be the moment in which we have undoubtedly entered the age of Pervasive Electrochemistry and it is a future task for us electrochemists to lead the society on this way.

Acknowledgements The author is indebted to Fritz Scholz for the invitation to contribute this article. Having had the privilege to learn from the best electrochemists, this is also a good moment to express the sincerest thanks to my teachers Joachim Walter Schultze, Manuel M. Lohrengel, Dieter Kolb, Masahiro Seo and Martin Stratmann. The financial support by the Austrian Federal Ministry of Science, Research and Economy and the National Foundation for Research, Technology and Development through funding of the Christian Doppler Laboratory for Combinatorial Oxide Chemistry (COMBOX) is gratefully acknowledged.
Funding Information Open access funding provided by Johannes Kepler University Linz.

Open Access This article is licensed under a Creative Commons Attribution 4.0 International License, which permits use, sharing, adaptation, distribution and reproduction in any medium or format, as long as you give appropriate credit to the original author(s) and the source, provide a link to the Creative Commons licence, and indicate if changes were made. The images or other third party material in this article are included in the article's Creative Commons licence, unless indicated otherwise in a credit line to the material. If material is not included in the article's Creative Commons licence and your intended use is not permitted by statutory regulation or exceeds the permitted use, you will need to obtain permission directly from the copyright holder. To view a copy of this licence, visit http://creativecommons.org/licenses/by/4.0/.

\section{References}

1. Heitz J, Plamadeala C, Muck M, Armbruster O, Baumgartner W, Weth A, Steinwender C, Blessberger H, Kellermair J, Kirner SV, Krüger J, Bonse J, Guntner AS, Hassel AW (2017) Femtosecond laser-induced microstructures on Ti substrates for reduced cell adhesion. Appl Phys A Mater Sci Process 123(12):734. https://doi.org/10.1007/s00339-017-1352

2. Muster TH, Trinchi A, Markley TA, Lau D, Martin P, Bradbury A, Bendavid A, Dligatch S (2011) A review of high throughput and combinatorial electrochemistry, Electrochim. Acta 56:9679-9699

3. Star Trek - Next generation, television series (1987)

4. Pötzelberger I, Mardare CC, Uiberlacker LM, Hild S, Hassel AW (2018) Optimum copper-palladium catalyst from a combinatorial library for sensitive non-enzymatic glucose sensors. Electrocatalysis 9(3):359-369

Publisher's note Springer Nature remains neutral with regard to jurisdictional claims in published maps and institutional affiliations. 